\title{
PEMANTAUAN KONSENTRASI KLOROFIL-A MENGGUNAKAN CITRA SATELIT TERRA-AQUA MODIS DI TELUK JAKARTA
}

\section{MONITORING OF CHLOROPHYLL-A CONCENTRATION USING TERRA-AQUA MODIS SATELITTE IMAGE IN JAKARTA BAY}

\author{
M. Salam Tarigan ${ }^{1}$ dan Ngurah N. Wiadnyana ${ }^{2}$ \\ ${ }^{1}$ Peneliti pada Pusat Penelitian Oseanografi - LIPI, Jakarta \\ E-mail: saltargir@yahoo.com \\ ${ }^{2}$ Peneliti pada Pusat Pengkajian dan Perekayasaan Teknologi Kelautan dan Perikanan, Badan Penelitian dan \\ Pengembangan Kelautan dan Perikanan - Kementerian Kelautan dan Perikanan, Jakarta
}

Diterima tanggal: 8 Juni 2013, diterima setelah perbaikan: 30 Juli 2013, disetujui tanggal: 1 Agustus 2013

\begin{abstract}
ABSTRAK
Kelimpahan klorofil-a dapat digunakan sebagai indikator kesuburan perairan dan kejadian biakan massal fitoplankton atau Harmfull Algal Blooms (HAB) di suatu perairan. Kemajuan teknologi satelit telah mampu menampilkan data digital yang memainkan peran penting dalam memberikan hasil pola sebaran horizontal klorofil-a di perairan laut secara cepat dan akurat. Tujuan penelitian ini adalah untuk pemantauan distribusi konsentrasi klorofil-a dengan teknologi penginderaan jauh menggunakan satelit Terra-Aqua MODIS. Pemantauan konsentrasi klorofil-a di perairan Teluk Jakarta dilakukan dalam periode April sampai September 2010. Analisis citra untuk memetakan sebaran konsentrasi klorofil-a dilakukan dengan algoritma menggunakan software ENVI dan ArcGIS. Dengan analisis citra di laboratorium, dihasilkan peta-peta sebaran konsentrasi klorofil-a di perairan Teluk jakarta. Pada peta spasial dan temporal sebaran konsentrasi klorofil-a ditunjukkan nilai konsentrasi klorofil-a tinggi $\left(>10 \mathrm{mg} / \mathrm{m}^{3}\right)$ di selatan perairan Teluk Jakarta, dengan luas sebarannya mencapai sepertiga dari luas teluk terjadi pada $22 \mathrm{Mei}-22$ September 2010. Hal ini mengindikasikan bahwa di perairan telah terjadi peningkatan kelimpahan fitoplankton dan sebagian menunjukkan ada dugaan terjadi Harmful Algal Blooms (HAB), sehingga mengakibatkan kematian ikan yang terdapat di pantai Ancol Teluk Jakarta.
\end{abstract}

Kata kunci: satelit Terra-Aqua MODIS, klorofil-a, Teluk Jakarta.

\begin{abstract}
The abundance of chlorophyll-a may be used as indicator of waters fertility and as Harmful Algal Blooms (HAB) event in the waters. Progress in satellite technology gives good advantages in presenting digital data to delivering with accurate and quickly the outstanding of horizontal distribution of chlorophyll-a in the waters. The present study aims to monitoring the concentration distribution of chlorophyll-a by remote sensing using satellite MODIS-Aqua Terra. Monitoring of chlorophyll-a concentration in Jakarta Bay was conducted in the period of April to September 2010. Image analysis to mapping the distribution of chlorophyll-a concentration was done with algorithms using ENVI and Arc GIS software. Based on image analysis in the laboratory, it came up with maps of the distribution of chlorophyll-a concentration in the waters. In the map it shows the spatial and temporal distribution of chlorophyll-a concentration of high value reaching $>10 \mathrm{mg} / \mathrm{m}^{3}$ in the southern waters of Jakarta Bay, with the extent of its spread in one third of the bay area. This indicates that the significant increase of phytoplankton abundance and in the part of location harmful algal blooms occurred causing the mortality in some fishes in Ancol waters of Jakarta Bay.
\end{abstract}

Keywords: Aqua-Terra MODIS satellite, chlorophyll-a, Jakarta Bay.

Pemantauan Konsentrasi Klorofil-a Menggunakan Citra Satelit Terra-Aqua MODIS di Teluk Jakarta 


\section{PENDAHULUAN}

Di perairan Teluk Jakarta terdapat sekitar 13 sungai yang bermuara, diantaranya S. Citarum, S. Marunda, S. Ciliwung, S. Sunter dan S. Pasenggarahan. Sungai-sungai tersebut sering memberikan tekanan antrofogenik terhadap ekosistem perairan teluk dan sekitarnya, khususnya pada musim penghujan. Tekanan antropogenik yang ke dalam perairan Teluk Jakarta dapat berupa limbah domestik dan industri, limbah minyak akibat padatnya lalulintas pelayaran di dalam perairan dan sekitar Teluk Jakarta dan pencemaran bakteriologis (Ruyitno, 2008). Kesuburan perairan pun sering mengalami peningkatan akibat dari masuknya nutrien yang terbawa oleh sungai-sungai yang bermuara di Teluk Jakarta (Muchtar, 2008; Simanjuntak, 2009; Damar, 2003), bahkan masuknya nutrien yang berlebih menyebabkan terjadinya eutrofikasi, yang berakhir pada terjadinya biakan massal fitoplankton yang sering menyebabkan kematian pada ikan (Wiadnyana, 1996; Sidabutar, 2008). Untuk itu pemantauan kualitas air di Teluk Jakarta dengan teknologi pengideraan jauh adalah penting agar perubahan negatif kondisi perairan dapat diketahui secara cepat sehingga dapat mengantisipasi dampak yang dapat ditimbulkan.

Klorofil-a merupakan pigmen yang terdapat pada fitoplankton yang berfungsi sebagai pengikat energi matahari sehingga terjadilah proses fotosintesis. Pentingnya klorofil fitoplankton sebagai suatu faktor ekologi terletak pada kegunaannya sebagai ukuran standing-stok fitoplankton dan ukuran potensial fotosintesa suatu perairan (Darecki et al., 2005; lvain et al., 2005). Klorofil merupakan salah satu parameter yang sangat menentukan produktivitas primer di laut, yang mana sebaran dan tinggi rendahnya konsentrasi klorofil sangat terkait dengan kondisi oseanografis suatu perairan (Wiadnyana, 1995). Konsentrasi klorofil-a di perairan dapat menggambarkan besarnya produktifitas primer (Anderson, 2005). Menurut Hediarti (2003), penginderaan jauh khlorofil-a adalah salah satu cara mengetahui keadaan laut dan proses-proses yang terjadi didalamnya berdasarkan nilai konsentrasi dari water-leaving radiance yang merupakan hasil interaksi antara sinar matahari dan perairan yang diterima oleh satelit. Klorofil menyerap cahaya berupa radiasi elektromagnetik pada spektrum kasat mata (visible). Misalnya, cahaya matahari mengandung semua warna spektrum kasat mata dari merah sampai violet, tetapi seluruh panjang gelombang unsurnya tidak diserap dengan baik secara merata oleh klorofil. Klorofil dapat menampung energi cahaya yang diserap oleh pigmen cahaya atau pigmen lainnya melalui fotosintesis, sehingga klorofil disebut sebagai pigmen pusat reaksi fotosintesis. Pada proses fotosintesis, tumbuhan hanya dapat memanfaatkan sinar dengan panjang gelombang tampak antara 400-700 nm (Gobel et al., 2006; Woerd et al., 2008).

Dengan menggunakan teknologi pengideraan jauh, beberapa peneliti dapat melakukan pemantauan kondisi perairan secara cepat, seperti: Wouthuyzen dan Siahainenia (1999) di perairan Teluk Kayeli dan Elpa Putih menggunakan satelit landsat 5 TM; Yoder dan Kennelly (2003), Pozdnyakov et al. (2003) dan Schollaert et al. (2004) telah membuat peta konsentrasi klorofil fitoplankton dengan menggunakan SEAWIFS. Maldonado (2008) mendeteksi harmful algal blooms (Habs), spesies dinoflagellate Cochlodinium polykrikoides (Margalef) di selatan Puerto Rico. Selanjutnya Ahn et al. (2001) melaporkan hasil pengembangan model pendugaan konsentrasi klorofil-a dan material padatan tersuspensi dari citra satelit. Begitu pula Brivio et al. (2001) mendeteksi perubahan konsentrasi klorofil-a di Danau Garda dengan menggunakan citra landasat TM. Dengan menggunakan citra satelit Terra-Aqua MODIS, dilakukan pemantauan konsentrasi klorofil-a di perairan Teluk Jakarta dengan tujuan untuk mengetahui pola perubahan konsentrasi klorofil-a secara spasial dan temporal. Informasi yang diperoleh ini diharapkan dapat acuan dalam pemantauan kualitas lingkungan di perairan Indonesia.

\section{BAHAN DAN METODE}

Pengamatan lapangan dilakukan pada periode April - Mei 2010 dan Juli - September 2010 pada 10 stasiun di perairan Teluk Jakarta (Gambar 1). 


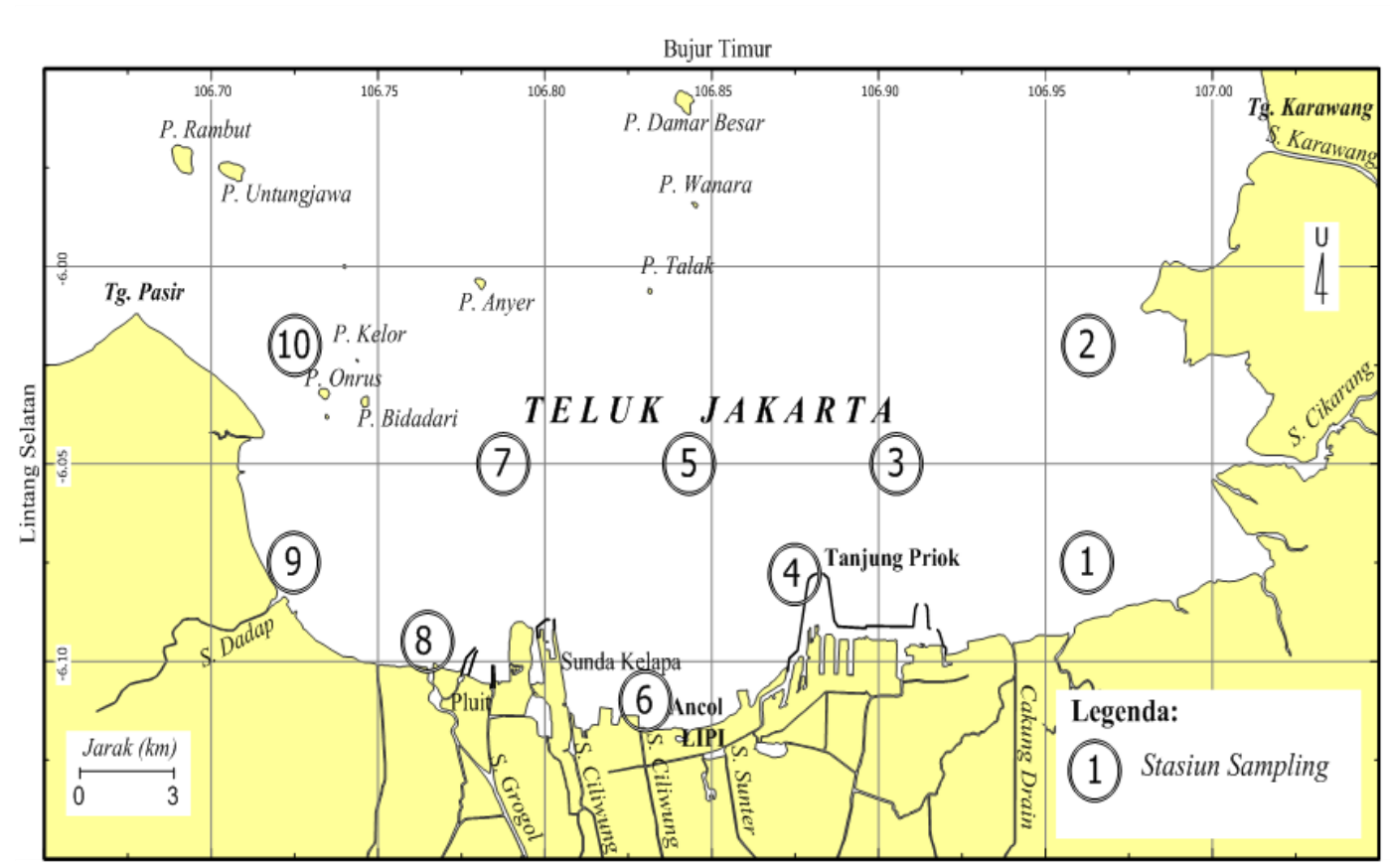

Gambar 1. Peta pokasi penelitian di Teluk Jakarta.

Figure 1. Map showing research location in Jakarta Bay.



Gambar 2. Pendugaan konsentrasi klorofil-a di Teluk Jakarta. Figure 2. Chlorophyll concentration estimate in Jakarta Bay.

Dimana, $\mathbf{Y}$ adalah sebaran konsentrasi klorofil-a dan $\mathbf{X}$ adalah kromasiti merah $=((\mathrm{ND}$ band merah $) /(\mathrm{ND}$ band merah + ND band hijau + ND band biru).

Citra satelit yang digunakan dalam penelitian ini adalah citra satelit Terra-Aqua MODIS (14 scene), yang melewati daerah Teluk Jakarta dengan selang waktu satu atau dua hari, satu citra untuk di download selama 6 Jam. Citra MODIS level IB yang telah terkalibrasi nilai radiansnya diperoleh dari NASA dengan alamat web: http://rafidfire.sci.gsfc.nasa.gov/ realtime. Sensor
MODIS dari satelit Terra memiliki sensivitas radiometrik tinggi (16 bit), terdiri atas 36 band dengan kisaran panjang gelombang 0,4-14,4 um. Dua band pertama (band 1 dan 2) memiliki resolusi $250 \mathrm{~m}, 5$ band berikutnya memiliki resolusi 500 $\mathrm{m}$, sedangkan 29 band sisanya memiliki resolusi $1000 \mathrm{~m}$ dan bentangan pengamatan seluas $2.330 \mathrm{x}$ $2.330 \mathrm{~km}$. Pada kegiatan ini hanya digunakan 3 
band pada panjang gelombang tampak, yaitu band biru (MODIS band 3: 0,459-0,479 um), hijau (MODIS band 4: 0,545-0,645 um) dan merah (MODIS band 1: 0,620-0,670 um). Untuk memetakan konsentrasi klorofil-a di perairan Teluk Jakarta digunakan formula Wouthuyzen et al. (2006) seperti pada Gambar 2.

\section{HASIL DAN PEMBAHASAN}

Citra MODIS sebelum digunakan terlebih dahulu dikoreksi secara radiometrik dan geometrik (Ricards, 1986; Welch et al., 1985). Kemudian dilakukan pemotongan citra sesuai daerah yang dibutuhkan, pembuatan citra komposit, pemisahan laut dan daratan atau prosedur analisis citra mengacu pada Wouthuyzen et al. (2006). Untuk pemetaan sebaran konsentrasi klorofil-a di perairan Teluk Jakarta dari seluruh citra (14 citra) yang digunakan yakni: 24 April 2010; 19, 21, 24, dan 28 Mei 2010; 9, 13, dan 27 Juni 2010; 6 dan 24 Juli 2010; 12, 14, 19, dan 22 September 2010. Selanjutnya dilakukan klasifikasi citra sebaran konsentrasi klorofil-a di perairan Teluk Jakarta dan hasilnya berturut-turut disajikan pada Gambar 3 .

Peta sebaran konsentrasi klorofil-a diperairan Teluk Jakarta pada 24 April 2010 (Gambar 3) memperlihatkan nilai konsentrasi klorofil-a yang tinggi di sekitar perairan pantai barat, selatan dan timur teluk yang nilainya mencapai $10 \mathrm{mg} / \mathrm{m}^{3}$ dan luas sebarannya sekitar setengah dari Teluk Jakarta. Kearah tengah menuju utara teluk, nilai konsentrasi klorofil-a semakin menurun mencapai sekitar $0,25 \mathrm{mg} / \mathrm{m}^{3}$, dan luas sebarannya lebih tipis dari pada sebaran nilai konsentasi klorofil-a yang tinggi. Nilai konsentrasi klorofil-a pada 19 Mei 2010 menurun mencapai $0,75-1,50 \mathrm{mg} / \mathrm{m}^{3}$ dan merata di seluruh Teluk Jakarta. Pada 21 Mei 2010, nilai konsentrasi klorofil-a mulai meningkat mencapai $>10 \mathrm{mg} / \mathrm{m}^{3}$, yakni di sekitar pantai timur, selatan dan barat teluk dan luas sebarannya masih sangat sempit, dan nilai konsentrasi klorofil-a yang rendah sebarannya kearah tengah menuju ke utara teluk yang sebarannya sangat luas. Kondisi ini sesuai dengan laporan dari Sidabutar (2008), yang mengatakan kondisi kelimpahan fitiplankton yang kerap melimpah hampir di seluruh Teluk Jakarta.
Pada 24 Mei 2010, terjadi peningkatan secara mendadak konsentrasi klorofil-a (mencapai >10 $\mathrm{mg} / \mathrm{m}^{3}$ ) dan sebarannya sangat luas mencapai sekitar tiga perempat Teluk Jakarta. Nilai konsentrasi klorofil-a sekitar $5 \mathrm{mg} / \mathrm{m}^{3}$ hanya ditemukan kearah utara teluk dengan luas sebarannya sangat sempit (Gambar 3). Sebaran konsentrasi klorofil-a pada 28 Mei 2010 berbeda dengan sebaran konsentrasi klorofil-a tanggal 24 Mei 2010 yakni, nilainya menurun hampir merata diseluruh perairan Teluk Jakarta dengan nilai sekitar $5 \mathrm{mg} / \mathrm{m}^{3}$ dan sebarannya meluas hampir seluruh Teluk Jakarta, kecuali kearah laut (utara) teluk dimana nilai sebaran konsentrasi klorofil-a menurun kembali hingga $0,25 \mathrm{mg} / \mathrm{m}^{3}$. Sedangkan di sebelah barat dan timur Teluk Jakarta nilainya masih tinggi mencapai $10 \mathrm{mg} / \mathrm{m}^{3}$ dan luas sebarannya sangat sempit dibandingkan dengan luas sebaran konsentrasi klorofil-a yang rendah (Gambar 3).

Dalam peta sebaran konsentrasi klorofil-a pada 9 Juni 2010 juga ditemukan menurun kearah barat laut, tengah dan kearah laut (utara) teluk nilainya mencapai $0,25 \mathrm{mg} / \mathrm{m}^{3}$ dengan luas sebarannya sangat sempit. Sedangkan di bagian barat dan bagian pantai timur Teluk Jakarta ada kenaikan nilai konsentrasi klorofil-a yakni mencapai 10 $\mathrm{mg} / \mathrm{m}^{3}$ dan luas sebarannya juga sempit seperti tampak pada Gambar 3. Pada peta sebaran konsentrasi klorofil-a pada 13 Juni 2010 (Gambar 3) terlihat bahwa nilai konsentrasi kolorofil-a menurun drastis mencapai $0,25 \mathrm{mg} / \mathrm{m}^{3}$ dari tengah kearah laut (utara) yang luas sebarannya sekitar tiga perempat teluk. Sedangkan di pantai bagian barat, selatan dan timur perairan Teluk Jakarta nilai konsentrasi klorofil-a masih ditemukan tinggi berkisar antara $5-10 \mathrm{mg} / \mathrm{m}^{3}$ dan sebarannya seperempat teluk. 


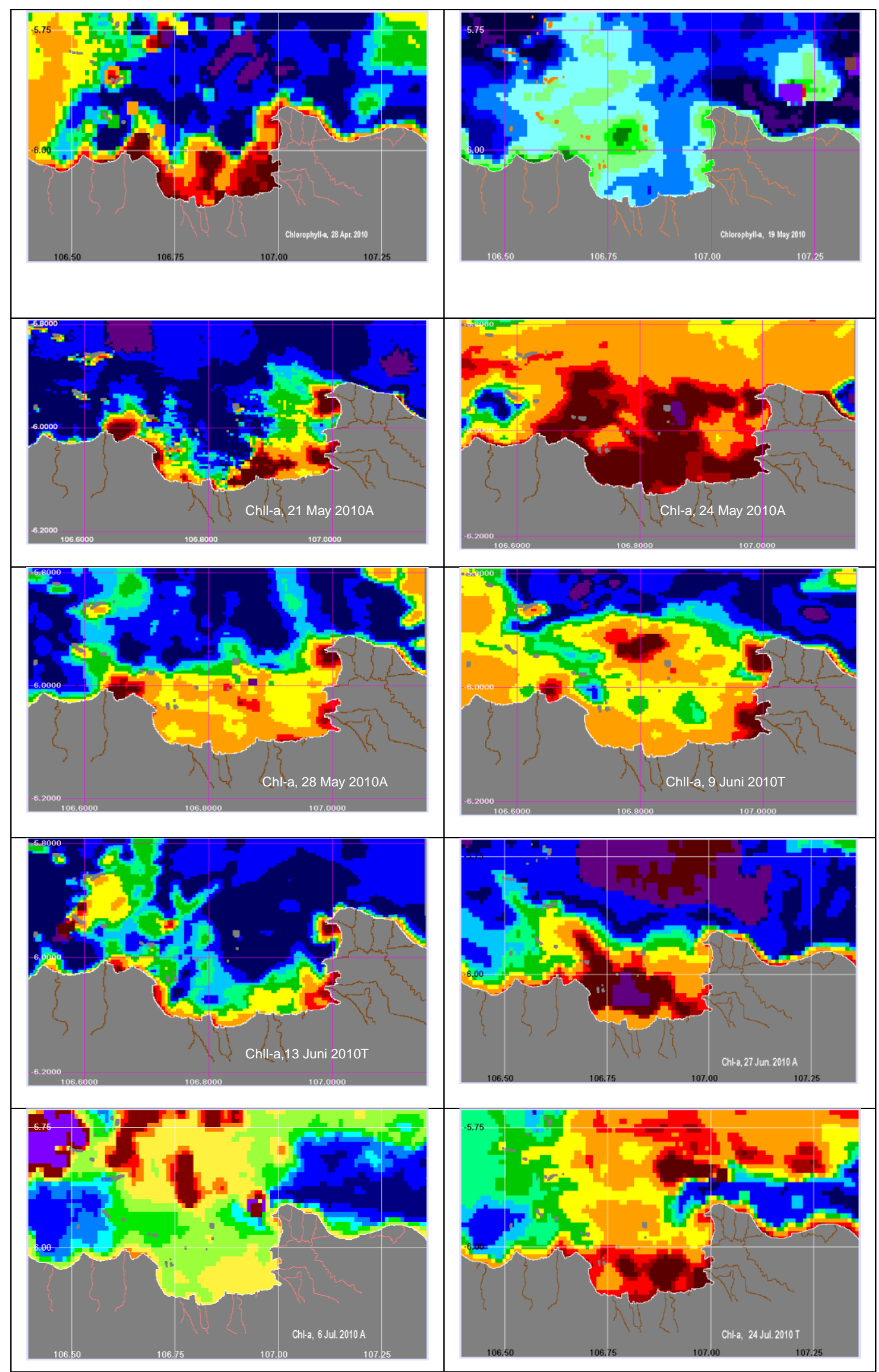



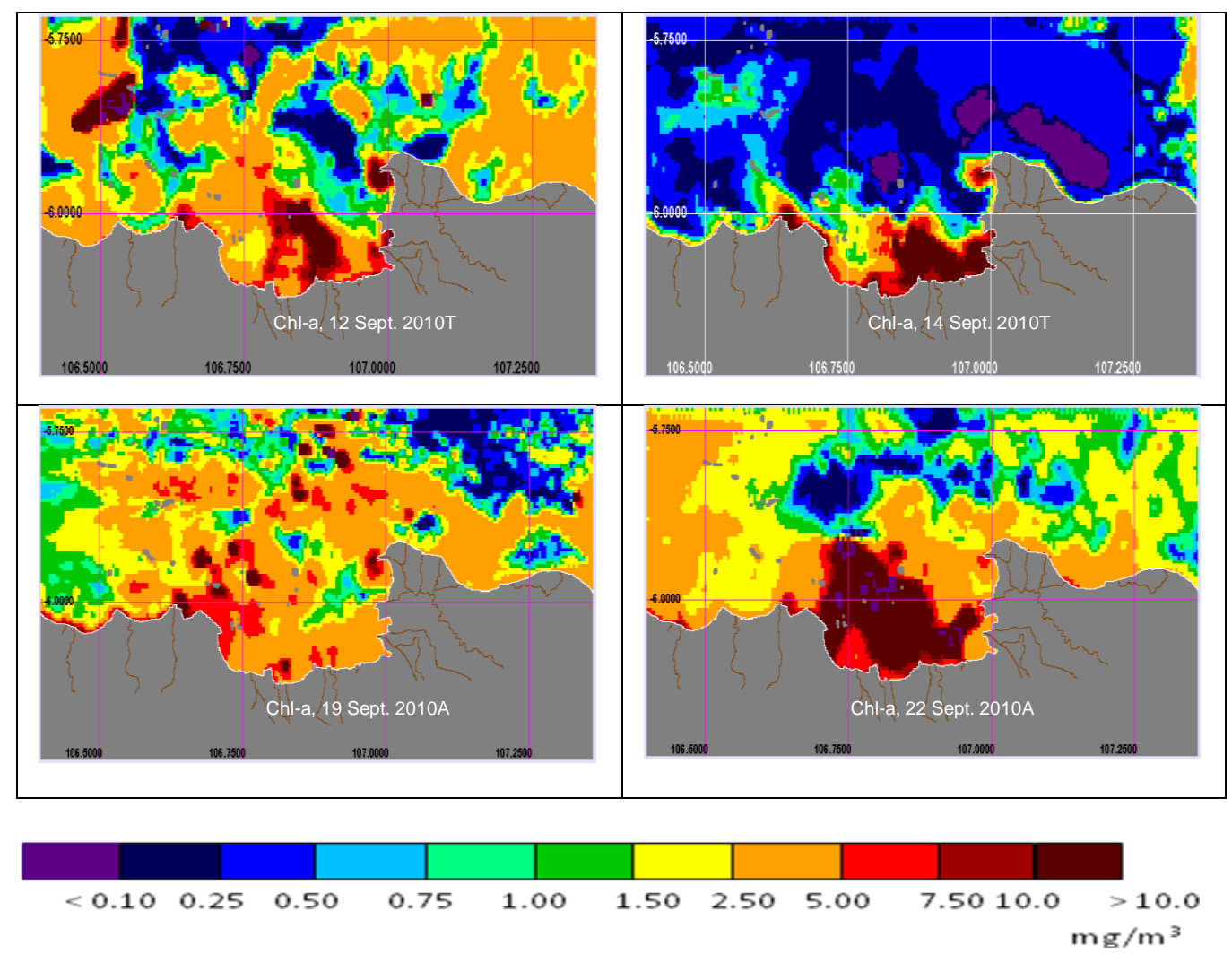

Gambar 3. Sebaran Konsentrasi klorofil-a di Teluk Jakarta.

Figure 3. Distribution of chlorophyll concentration in Jakarta Bay.

Pada 27 Juni 2010 nilai konsentrasi klorofil-a terjadi sebalikya dengan nilai konsentrasi klolofil-a tanggal 13 Juni 2010 yakni ada peningkatan secara mendadak mencapai $>10 \mathrm{mg} / \mathrm{m}^{3}$ di sekitar pantai barat dan dari tengah teluk kearah pantai timur perairan Teluk Jakarta. Nilai konsentrasi klorofil-a yang tinggi ditemukan sebarannya mencapai kurang lebih setengah teluk yakni kearah laut (utara) Teluk Jakarta. Sedangkan nilai konsentrasi klorofil-a rendah yakni berkisar antara $0,1-2,50$ $\mathrm{mg} / \mathrm{m}^{3}$ ditemukan sebarannya di tengah dan juga ke arah utara Teluk Jakarta seperti terlihat dalam Gambar 3. Begitu pula pada 6 Juli 2010, nilai konsentrasi klorofil-a (Gambar 3) ditemukan menurun di pantai barat, selatan dan timur berkisar antara $0,75-2,50 \mathrm{mg} / \mathrm{m}^{3}$ dan sebarannya mencapai tiga perempat Teluk Jakarta. Sedangkan kearah laut (utara) dan pantai timur ke utara perairan Teluk Jakarta terjadi peningkatan mencapai $>10$ $\mathrm{mg} / \mathrm{m}^{3}$ dan luas sebarannya sangat sempit.

Pola sebaran konsentrasi klorofil-a pada 24 Juli 2010 berbeda dengan pola sebaran yang terjadi pada 6 Juli 2010 (Gambar 3) secara keseluruhan terjadi peningkatan nilai konsentrasi klorofil-a mencapai $>10 \mathrm{mg} / \mathrm{m}^{3}$ ditemukan di sekitar pantai timur, di tengah maupun di timur laut perairan Teluk Jakarta dan sebarannya sangat luas mencapai setengah Teluk Jakarta. Sedangkan nilai konsentrasi klorofil-a yang rendah berkisar antara $0,50-1,5 \mathrm{mg} / \mathrm{m}^{3}$ ditemukan di sekitar utara pantai timur perairan Teluk Jakarta dengan luas sebarannya sangat sempit.

Pada 12 September 2010, nilai konsentrasi klorofil-a di perairan Teluk Jakarta masih tinggi (> $10 \mathrm{mg} / \mathrm{m}^{3}$ ) ditemukan di sebagian pantai selatan dan kearah tengah teluk serta luas sebarannya mencapai seperempat perairan Teluk Jakarta. Nilai sebaran konsentrasi klorofil-a yang rendah berkisar antara $0,25-1,50 \mathrm{mg} / \mathrm{m}^{3}$ ditemukan di sebagian pantai timur kearah utara perairan Teluk Jakarta (Gambar 3). Pada 14 September 2010 dari tengah teluk kearah laut dan kearah barat perairan Teluk Jakarta nilai konsentrasi klorofil-a ditemukan rendah berkisar antara $0,1-1,5 \mathrm{mg} / \mathrm{m}^{3}$ dengan luas sebaran mencapai setengah teluk perairan Teluk Jakarta, sedangkan sebagian pantai selatan serta pantai timur kearah tengah teluk nilai konsentrasi klorofil-a ditemukan tinggi (> $\left.10 \mathrm{mg} / \mathrm{m}^{3}\right)$ dengan 
luas sebarannya mencapai sekitar sepertiga perairan Teluk Jakarta. Nilai konsentrasi ini lebih tinggi dari nilai tertinggi yang tercatat di Teluk Jakarta pada 20 tahun lalu (Sutomo dan Hutagalung, 1994). Hal ini menandakan bahwa Teluk jakarta telah mengalami penyuburan perairan kemungkinan diakibatkan oleh semakin tinggi konsentrasi unsur-unsur hara di dalam perairan.

Pada 17 September 2010 di sekitar perairan pantai Ancol ditemukan banyak ikan terapung yang sudah mati yang kemungkinan disebabkan oleh menurunnya konsentrasi oksigen di perairan akibat terjadinya peningkatan konsentrasi fitoplankton yang signifikan. Pada 19 September 2010, di sebagian utara dan sebagian barat perairan Teluk Jakarta terjadi peningkatan nilai konsentrasi klorofil-a berkisar antara 2,50-7,50 mg/ $\mathrm{m}^{3}$ dengan luas sebarannya mencapai sekitar tiga perempat perairan Teluk Jakarta, sedangkan sebagian pantai timur perairan Teluk Jakarta nilai konsentrasi klorofil-a menurun mencapai sekitar $1,50 \mathrm{mg} / \mathrm{m}^{3}$ dan luas sebaranya sangat tipis.

Sebaran konsentrasi klorofil-a pada 22 September 2010 di tengah teluk dan sebagian pantai barat, selatan dan timur meningkat mencapai $>10 \mathrm{mg} / \mathrm{m}^{3}$, sedangkan di utara sebagian Teluk Jakarta terjadi penurunan mencapai $0,25 \mathrm{mg} / \mathrm{m}^{3}$ seperti ditunjukkan pada Gambar 3. Menurut Li et al. (2002) dan Wouthuyzen et al. (2006), konsentrasi klorofil-a merupakan indikator untuk mengetahui terjadinya bloming fitoplankton (HABs), apabila konsentrasi klorofil-a mencapai $10 \mathrm{mg} / \mathrm{m}^{3}$ atau > $10 \mathrm{mg} / \mathrm{m}^{3}$ di perairan tersebut sedang terjadi kelimpahan fitoplankton. Berdasarkan hasil pengamatan pada 24 April, 24 Mei, 27 Juni, 24 Juli, 12. 14, dan 22 September 2010, konsentrasi klorofil-a di sebagian Teluk Jakarta ditemukan tinggi $>10 \mathrm{mg} / \mathrm{m}^{3}$, dimana pada periode diatas diperkirakan sedang terjadi biakan massal fitoplankton.

\section{KESIMPULAN DAN SARAN}

Dengan pemantauan menggunakan teknologi penginderaan jauh dapat ditunjukkan perubahan kondisi perairan dari waktu ke waktu secara cepat. Peningkatan nilai konsentrasi klorofil-a dapat berubah ubah, dengan nilai konsentrasi yang tinggi $\left(>10 \mathrm{mg} / \mathrm{m}^{3}\right)$ terjadi pada 24 April, $24 \mathrm{Mei}, 27$
Juni, 24 Juli, 12, 14, 22 September 2010, mengindikasikan sedang terjadi biakan massal fitoplankton. Sedangkan pada periode lainnya tidak ditemukan adanya indikasi terjadinya kelimpahan fitoplankton yang tinggi, yang ditandai dengan rendahnya nilai konsentrasi klorofil-a.

\section{UCAPAN TERIMA KASIH}

Penulis mengucapkan banyak terima kasih kepada Ir. Tumpak Sidabutar, M.Sc sebagai koordinator penelitian dan Prof. Dr. Ir. Sam Wouthuyzen, M.Sc atas masukan dan perbaikan terhadap tulisan ini.

\section{DAFTAR PUSTAKA}

Ahn, Y. H., J. E. Moon dan S. Gallegos. 2001. Development of Suspended Particulate Matter Algorithms for Ocean Color Remote Sensing. Korean Journal of Remote Sensing 17 (4): 285-295.

Anderson, T.R. 2005. Plankton Functional Type Modelling: Running Before We Can Walk. Journal of Plankton Research 27 (11): 10731081.

Brivio, P.A., C. Giardino dan E. Zilioli. 2001. Determination of Chlorophyll Concentration Changes in Lake Garda Using an Image-based Radiative Transfer Code for Landsat TM Images. International Journal of Remote Sensing 22: 487-502.

Damar, A. 2003. Effect of Enrichment on Nutrient Dynamics, Phytoplankton Dynamics and Productivity in Indonesian Tropical Waters: A Comparison Between Jakarta Bay, Lampung Bay and Semangka Bay. Doctoral diss., Kiel: der MathematischNaturwissenechaftlichen Fakultät. Christian-Albrechts-Universität.

Darecki, M., S. Kaczmarek dan J. Olszewski. 2005. SeaWiFS Chlorophyll Algorithms for the Southern Baltic. International Journal of Remote Sensing 26 (2): 247-260.

Giardino, C., M. Pepe, P.A. Brivio, P. Ghezzi dan E. Zilioli. 2001. Detecting Chlorophyll, Secchi Disk Depth and Surface Temperature in A Sub-Alpine Lake Using Landsat Imagery. Science of the Total Environment 268: 19-29. 
lvain, S., C. Moulin, Y. Dandonneau dan F. M. Breon. 2005. Remote Sensing of Phytoplankton Groups in Case 1 Waters from Global SeaWiFS Imagery. Deep-Sea Research Part I. Oceanographic Research Papers 52 (11): 1989-2004.

Kloiber, S. M., P. L. Brezonik, L. G. Olmanson dan M. E. Bauer. 2002. A Procedure for Regional Like Water Clarity Assessment Using Landsat Multispectral Data. Remote Sensing of Environment 82: 38-47.

Li, H. P., G.C. Gong dan T.M. Hsiung. 2002. Phytoplankton Pigment Analysis by HPLC and Its Application in Algal Community Investigations. Bot. Bull. Acad. Sin 43: $283-$ 290.

Maldonado, D.J. 2008. Spectral Properties and Population Dynamics of the Harmful Cochlodinium polykrikoides (Margalef) In Southwestern Puerto Rico. PhD diss., University of Puerto Rico Mayagüez Campus.

Miller, P. I., J. D. Shutler, G. F. Moore dan S.B. Groom. 2006. SeaWiFS Discrimination of Harmful Algal Bloom Evolution. International Journal of Remote Sensing 27: 2287-2301.

Muchtar, M. 2008. Fluktuasi Kandungan Zat Hara Fosfat, Nitrat dan Silikat di Teluk Jakarta. Kajian Perubahan Ekologis Perairan Teluk Jakarta. P2O- LIPI: 101-111.

Pozdnyakov, D. V., L. H. Pettersson, O. M. Johannessen, A. V. Lyaskovsky, N. N. Filatov dan L. P. Bobylev. 2003. SeaWiFS Maps Water Quality Parameters of the White Sea. Int. J. Rem. Sens., 24: 40654071.

Richards, J.A. 1986. Remote Sensing Digital Image Analysis. Berlin, Germany: Springer-Verlag. $281 \mathrm{pp}$.

Ruyitno, 2008. Kualitas Perairan Teluk Jakarta Ditinjau dari Aspek Bakteriologi: A Review (suatu tinjauan). Kajian Perubahan Ekologis Perairan Teluk Jakarta. P2O-LIPI:193-210.

Schollaert, S.E., T. Rossby dan J. A. Yoder. 2004. Gulf Stream Cross-Frontal Exchange: Possible Mechanisms to Explain Interannual Variations in Phytoplankton Chlorophyll the Slope Sea During the SeaWiFS years. DeepSea Research II, 51 (2004) 173-188.

Sidabutar, T. 2008. Kondisi Fitoplankton di Teluk Jakarta Kajian Perubahan Ekosisten
Perairan Teluk Jakarta. Kajian Perubahan Ekologis Perairan Teluk Jakarta. P2OLIPI: 113-133.

Simanjuntak, M. 2009. Kandungan Zat Hara di Perairan Teluk Jakarta. Prosiding Pertemuan Ilmiah Tahunan VI ISOI 2009. Ikatan Sarjana Oseanologi Indonesia Jakarta, 302-315.

Suh, Y.S., L.H. Jang, N.K. Lee dan J. Ishizaka. (2004a). Feasibility of Red Tide Detection Around Korean Waters Using Satellite Remote Sensing. J. Fish. Sci. Tech 7 (3): 148-162.

Sutomo dan H.P. Hutagalung. 1994. Pengamatan Kandungan Klorofil-a, di Perairan Muara Sunter, Teluk Jakarta, 1993. Prosiding Seminar Pencemaran Laut. Puslitbang Oseanologi - LIPI. Hal. 137 - 142.

Welch, T.R., J.R. Jordan, and M. Ehlers. 1985. Comparative Evaluation of the Geodetic Accuracy and Cartographic Potential of Landsat-4 and -5 Thematic Mapper Image Data. Photogrammetric Engineering and Remote Sensing 51 (9): 1249-1262.

Woerd, V., Hans, dan R. Pasterkamp. 2008. HYDROPT: A Fast and Flexible Method to Retrieve Chlorophyll-a from Multispectral Satellite Observations of Optically Complex Coastal Waters. Remote Sensing of Environment 112: 1795-1807.

Wiadnyana, N. N. 1995. Comparison of plankton productivity during and after upwelling periods in the Banda Sea, Moluccas, Eastern Indonesia. Proceedings of The International Seminar On Marine Fisheries Environment, March 9-10, 1995, Rayong Resort, Rayong, Thailand. Eastern Marine Fisheries Development Center - Japan International Cooperation Agency. Hal. 157-170.

Wiadnyana, N. N. 1996. Mikroalga Berbahaya di Perairan Indonesia. Oseanologi dan Limnologi di Indonesia 29: 15-28.

Wouthuyzen, S., M.S. Tarigan, E. Kusmanto, H. Indarto dan Sugarin. 2006. Pemantauan Kualitas Perairan Teluk Jakarta untuk Memprediksi Mark Algae dengan Satelit Terra dan Aqua MODIS. Laporan Penelitian Kompetitif Jabopunjur-LIPI.

Wouthuyzen S. dan A. R. Siahainenia. 1999. Chlorophyll-a Concentration in Kayeli, Ambon and Elpaputih Bays, Maluku Province, Indonesia Estimated from 
Landsat-5 TM Data and its Relation with the Meteorological Parameters. Proc. $9^{\text {th }}$ JSPS Joint Sem. Fish. Sci: 29-39pp.

Yoder, J.A dan M. A Kennelly. 2003. Seasonal and ENSO Variability in Global Ocean Phytoplankton Chlorophyll Derived from 4 Years of SeaWiFS Measurements. Global Biogeochemical Cycles 17 (4): 1-14. 